\title{
Nova espécie de Zischkaita Bechyné e notas taxonômicas em Galerucini (Coleoptera, Chrysomelidae, Galerucinae)
}

\author{
Luciano de A. Moura
}

Museu de Ciências Naturais, Fundação Zoobotânica do Rio Grande do Sul. Caixa Postal 1188, 90001-970 Porto Alegre, Rio Grande do Sul, Brasil. E-mail: Imoura@cpovo.net

\begin{abstract}
New species of Zischkaita (Bechyné) and taxonomic notes on Galerucini (Coleoptera, Chrysomelidae, Galerucinae). A new species of Zischkaita Bechyné, 1956, Z. serrana sp. nov. are described from São Francisco de Paula and Cambará do Sul, Rio Grande do Sul State, Brazil. Two new combinations are proposed: Zischkaita bucki (Bechyné \& Bechyné, 1962), comb. nov., removed from Isotes and Cochabamba volxemi (Baly, 1889), comb. nov., transferred from Paranapiacaba.
\end{abstract}

KEY WORDS. Neotropical, new combinations, new species, South Brazil, taxonomy.

O gênero Zischkaita Bechyné, 1956 foi estabelecido para incluir as espécies similares a Isotes (Synbrotica sensu Bechyné) que possuem a margem do tórax com maior quantidade de pontos setíferos e os élitros com pêlos dispostos esparsamente, sem fileiras organizadas. Atualmente o gênero é composto por seis espécies distribuídas na Região Neotropical: três andinas, Zischkaita boliviensis Bechyné, 1956 (Bolívia), Z. jeronyma Bechyné, 1958 (Peru) e Z. metachroma Bechyné \& Bechyné, 1970 (Bolívia); duas amazônicas, Z. pilifera (Weise, 1921) e Z. tapajoensis Bechyné \& Bechyné, 1970, do Amazonas e do Pará, respectivamente; e Z . pubipennis Bechyné, 1958, do Rio de Janeiro.

As instituições mencionadas no texto são: (DZUP) Coleção de Entomologia Pe J.S. Moure, Departamento de Zoologia, Universidade Federal do Paraná, Curitiba; (MAPA) Museu Anchieta, Porto Alegre; (MCNZ) Museu de Ciências Naturais, Fundação Zoobotânica do Rio Grande do Sul, Porto Alegre; (MNRJ) Museu Nacional, Universidade Federal do Rio de Janeiro, Rio de Janeiro; (MZSP) Museu de Zoologia, Universidade de São Paulo, São Paulo.

\section{Zischkaita bucki (Bechyné \& Bechyné, 1962) comb. nov.}

Synbrotica bucki Bechyné \& Bechyné, 1962: 31, 50; 1969: 73 (distr.); Smith \& Lawrence, 1967: 45; Wilcox, 1972: 385 (cat.).

Isotes bucki; Wilcox, 1975: 680 (cat.).

Ao examinar exemplares de Synbrotica bucki, verificou-se que a borda do protórax possui mais de quatro pontos setíferos a cada lado e a superfície elitral é dotada de pêlos esparsamente distribuídos, caracteres que se enquadram na descrição de Zischkaita dada por BECHYNÉ (1956).
Material examinado. BrasiL, Rio Grande do Sul: Caxias do Sul (Vila Oliva), holótipo fêmea, 17.II.1949 [sem nome do coletor] (MAPA); parátipos macho, fêmea, 17.II.1949 [sem nome do coletor] (MAPA); parátipos macho, fêmea, 2.II.1950 [sem nome do coletor] (MAPA); parátipo fêmea, 3.II.1952 [sem nome do coletor] (MAPA); parátipo macho, 14.II.1950 [sem nome do coletor] (MAPA); parátipo fêmea, 26.II.1950 [sem nome do coletor] (MAPA); parátipo fêmea, 18.II.1951 [sem nome do coletor] (MAPA); parátipo fêmea, 28.I.1950 [sem nome do coletor] (MAPA); parátipo fêmea , 12.II.1948, P.P. Buck leg. (MAPA); parátipo fêmea , 31.I.1952, P.P. Buck leg. (MAPA); parátipo fêmea , 31.I.1959, P.P. Buck leg. (MAPA); 2 fêmeas, II.1949 [sem nome do coletor] (MAPA); 2 machos, 18.I.1961 [sem nome do coletor] (MAPA); 2 machos, fêmea , 24.I.1963 [sem nome do coletor] (MAPA); macho (MCNZ 26417), 4 fêmeas (MCNZ 26416, 26418, 27226, 27227), 6.IV.1975, A. Lise leg.; São Francisco de Paula, parátipo fêmea, 10.I.1934 [sem nome do coletor] (MAPA); parátipo fêmea , I.1937 [sem nome do coletor] (MAPA); Pareci Novo, parátipo fêmea , 10.II.1949, P.P. Buck leg. (MAPA).

\section{Zischkaita serrana sp. nov. Figs $1-7$}

Macho. Cabeça amarela, com tegumento do vértice liso, brilhante e glabro; em alguns exemplares, uma mancha arredondada castanha no occipício; olhos globosos e projetados (Fig. 1), com pequenas cerdas dispostas na margem. Tubérculos anteníferos desenvolvidos, separados por sutura marcada. Fronte levemente convexa, brilhante, com pêlos esparsamente distribuídos. Clípeo curto, com pilosidade esparsa; labro brilhante, com borda apical emarginada, cobrindo a maior parte das mandíbulas; fileira de pêlos alongados disposta transversalmente. 

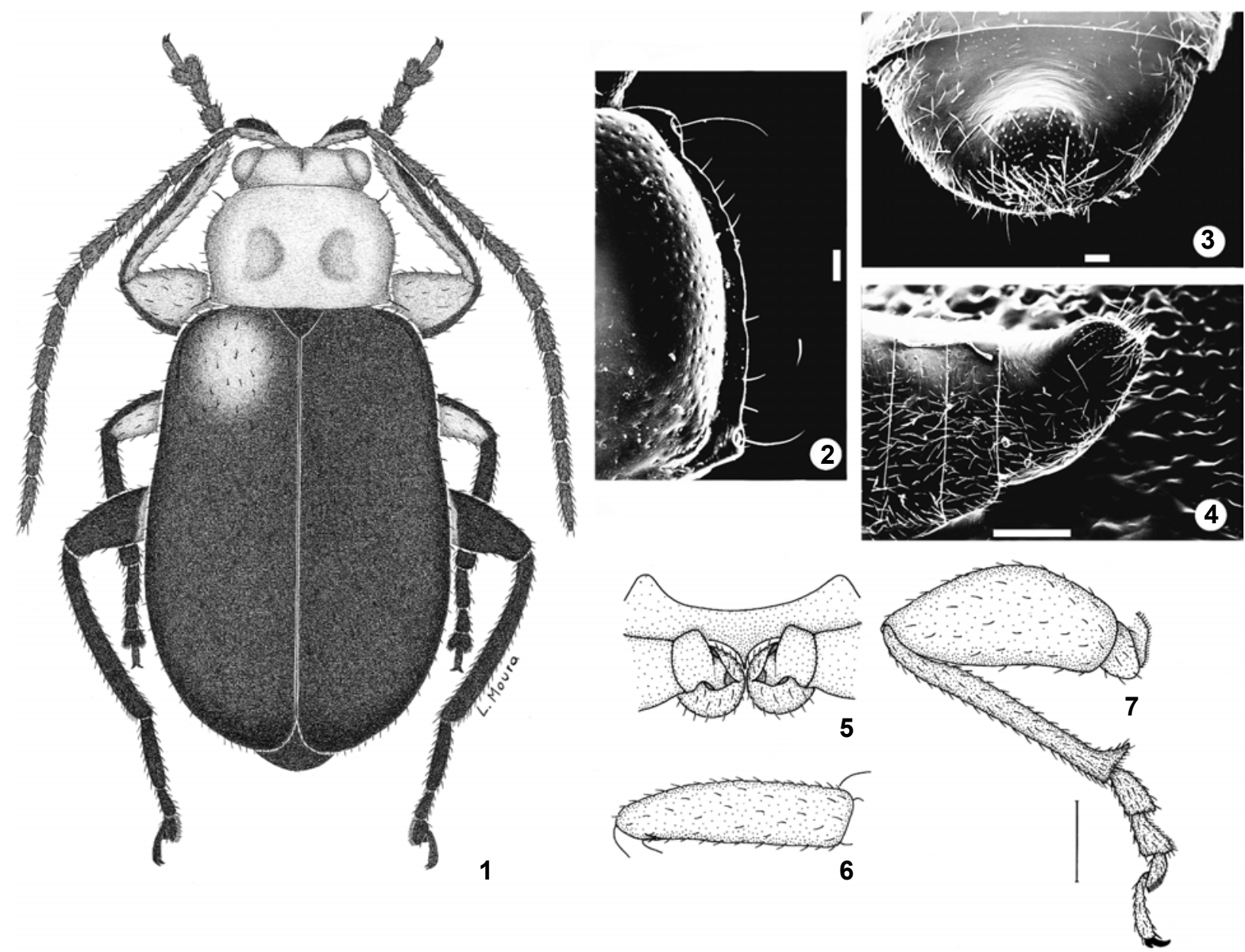

Figuras 1-7. 1. Zischkaita serrana sp. nov. (1) Holótipo macho, comprimento $6 \mathrm{~mm}$; (2) borda lateral do tórax, macho; (3-4) extremidade do abdome, macho: (3) ventral; (4) lateral; (5) base das pernas anteriores, macho; (6) fêmur anterior, fêmea; (7) perna anterior, macho. Escalas: figuras 2-3-0,1 $\mathrm{mm}$, figura $4-0,5 \mathrm{~mm}$, figuras 5-7 -0,5 $\mathrm{mm}$.

Antenas (Fig. 1) ultrapassam levemente o meio do corpo, castanho-escuras, exceto maior parte do escapo e face ventral dos antenômeros II-VIII (em alguns exemplares, II-XI) amarela. Pubescência nos artículos I e II escassa, mais densa a partir do III. Escapo subcilíndrico, de comprimento menor que a soma dos dois antenômeros seguintes; antenômero II aproximadamente a metade do comprimento do III e este menor que o IV, que é o mais longo de todos; V-XI subiguais, cerca de 0,6 vezes o comprimento do IV.

Protórax (Fig. 1) amarelo, brilhante, com uma depressão a cada lado do meio; pontuação esparsa, pouco marcada; lados arredondados, marginados, dotados de pêlos curtos espassados na borda e cada um dos ângulos com uma cerda longa (Fig. 2); pronoto aproximadamente 1,5 vezes mais largo que longo; mesosterno amarelo e metasterno preto. Escutelo preto, brilhante.

Élitros (Fig. 1) pouco brilhantes, pretos, com faixa amarela na margem interna da epipleura; pontuação esparsa e pouco marcada; pêlos eretos esparsamente distribuídos no disco e na margem externa. Largura umeral cerca de 1,3 vezes a largura da base do pronoto.

Fêmures amarelos, exceto faixa dorsal nos pro- e mesofêmures e $2 / 3$ dorsais (em alguns exemplares 1/3) dos metafêmures pretos; tíbias anteriores amarelas, dorsalmente pretas, intermediárias pretas com pequena área castanha na extremidade ventral e posteriores pretas com a porção ventro-lateral interna castanha. Pubescência nas pernas curta e uniforme, mais densa nas tíbias. Pernas anteriores: trocanteres (Fig. 5) projetados e aguçados anteriormente; fêmures (Fig. 7) engrossados, maior largura aproximadamente 1,5 vezes a maior largura dos mesofêmures; tíbias curvadas na extremidade (Fig. 7). Pernas intermediárias: porção basal do tarsômero I ventralmente com uma calosidade de tegumento glabro. Pernas posteriores: tíbias, lateralmente, levemente espessadas no meio.

Abdome preto, brilhante, com pêlos esparsamente distribuídos; ápice com uma protuberância de superfície pontua- 
da dotada de longos pêlos (Figs 3,4). Borda posterior do primeiro segmento abdominal com uma projeção central triangular aguda, direcionada postero-ventralmente.

Fêmea. Pernas anteriores com trocanteres não projetados e aguçados anteriormente; fêmures normais (Fig. 6); tíbias retas, sem curvatura na extremidade. Porção basal do mesotarsômero I ventralmente sem calosidade de tegumento glabro. Borda posterior do primeiro esterno abdominal reta, sem projeção central e último segmento abdominal sem protuberância ventral na extremidade.

Dimensões em $\mathrm{mm}$, respectivamente macho/fêmea. Comprimento total, 5,4-6,1/5,5-6,5; comprimento do élitro, 4,0-4,4/4,0-4,8; largura umeral, 2,1-2,4/2,1-2,6.

Material-tipo. Brasil, Rio Grande do Sul: Cambará do Sul, holótipo macho, 19.XII.1994, A. Bonaldo leg. (MCNZ 219974); parátipo macho, mesmos dados do holótipo (MCNZ 219975); parátipo fêmea, Rio Grande do Sul, São Francisco de Paula (ProMata), 2.V.1997, A Franceschini leg. (MCNZ 219963); 3 parátipos machos, São Francisco de Paula (Pro-Mata), 19-22.III.1998, L. Moura leg. (MCNZ 219971, 219972; MZSP); 7 parátipos fêmea, mesmos dados dos parátipos macho (MCNZ 219964, 219965, 219966, 219967, MNRJ, DZUP, MZSP).

Discussão taxonômica. Entre as espécies de Zischkaita, Z. serrana sp. nov. e Z. bucki (Bechyné \& Bechyné, 1962), comb. nov. são as únicas com os fêmures anteriores dilatados nos machos. A nova espécie difere de Z. bucki por apresentar élitros totalmente pretos, exceto uma faixa amarela na margem interna da epipleura; em $Z$. bucki, os élitros são menos brilhantes e possuem dois padrões de colorido: um com os élitros pretos e faixa amarela sutural que acompanha a borda até os úmeros e outro totalmente amarelo. Além disso, machos de $Z$. serrana possuem as pernas anteriores com trocanteres projetados, aguçados, protíbias curvadas na extremidade, pernas intermediárias com a porção basal do tarsômero I ventralmente com calosidade glabra, tíbias posteriores levemente espessadas no meio, abdome protuberante na extremidade apical e com projeção central aguda na borda posterior do primeiro segmento; tal dimorfismo sexual não é observado em $Z$. bucki.

Etimologia. O nome específico refere-se aos Campos de Cima da Serra, região serrana do Estado do Rio Grande do Sul onde foram coletados os exemplares.

\section{Cochabamba volxemi (Baly, 1889) comb. nov.}

Diabrotica volxemi Baly, 1889: 253; Baly in Gahan, 1891: 417, 440.

Synbrotica volxemi; Bechyné, 1956: 275.

Paranapiacaba volxemi; Bechyné, 1958: 562; Bechyné \&
Bechyné, 1962: 48 (distr.); Smith \& Lawrence, 1967: 143, 151; Wilcox, 1972: 348 (cat.).

Baly (1889) descreveu Diabrotica volxemi com base em duas fêmeas procedentes do Brasil, sem especificar a localidade; Bechyné (1956) tranferiu-a para o gênero Synbrotica e posteriormente (BEChyNé 1958), ao propor Paranapiacaba, alocou-a no novo gênero. Pelo metepisterno revestido por densa pilosidade, esta espécie é transferida para Cochabamba Bechyné, 1955.

Material examinado. Brasil, São Paulo: Campos do Jordão, macho, X.1959, J. Halik leg. (MCNZ).

\section{AGRADECIMENTOS}

A Cleodir J. Mansan, pela execução das fotografias junto ao Laboratório de Microscopia Eletrônica, Fundação Zoobotânica do Rio Grande do Sul.

\section{REFERÊNCIAS BIBLIOGRÁFICAS}

BALY, J.S. 1889. Diagnoses of uncharacterized species of Diabrotica. The Entomologist's Monthly Magazine, London, 25: 251-254.

Bechyné, J. 1956. Reise des Herrn G. Frey in Südamerika: Galerucidae (Col. Phytophaga). Entomologische Arbeiten, Tutzing, 7 (1): 241-358.

. 1958. Notizen zu den neotropischen Chrysomeloidea (Col. Phytophaga). Entomologische Arbeiten, Tutzing, 9 (2): 478-706.

BECHYNÉ, J. \& B. S. DE BECHYNÉ. 1962. Liste der bisher in Rio Grande do Sul gefundenen Galeruciden. Pesquisas Zoologia, São Leopoldo, $15: 5-68$.

. 1969. Die Galerucidengattungen in Sudbrasilien. Iheringia, Série Zoologia, Porto Alegre, (36): 3-110.

GaHAN, C.J. 1891. On the South American species of Diabrotica. Part II. The Transactions of the Entomological Society of London, London, 1891: 415-472.

SMith, R.F. \& J.F. LAWRENCE. 1967. Clarification of the status of the type specimens of Diabroticites (Coleoptera, Chrysomelidae, Galerucinae). University of California Publications in Entomology, Bekerley, 45: 1-168.

WILCoX, J.A. 1972. Coleopterorum Catalogus. Chrysomelidae: Galerucinae. Gravenhage, W. Junk, vol. 78, \# 2, $2^{\text {nd }}$ ed., p. 221-431.

. 1975. Coleopterorum Catalogus. Chrysomelidae: Galerucinae - Addenda et Index. Gravenhage, W. Junk, vol. 78, \# 4, $2^{\text {nd }}$ ed., p. 667-770.

Recebido em 17.VI.2003; aceito em 26.X.2003. 